\title{
Redução dos sintomas causados pela Xylella fastidiosa subsp. pauca por meio de aplicação de benzotiadiazole e silício
}

\author{
Juliana Camargo Martinati( ${ }^{(1)}$, Paulo Teixeira Lacava(2), Sandra Kazue Shishido Miyasawa(1), Sylvia Dias Guzzo ${ }^{(3)}$, \\ João Lúcio Azevedo ${ }^{(2)}$ e Siu Mui Tsai ${ }^{(1)}$
}

\begin{abstract}
(1)Centro de Energia Nuclear na Agricultura, Lab. de Biologia Celular e Molecular, Av. Centenário, № 303, Caixa Postal 96, CEP 13400-970 Piracicaba, SP. E-mail: jumarti@cena.usp.br, sandramiyasawa@uol.com.br, tsai@cena.usp.br (2)Escola Superior de Agricultura Luiz de Queiroz, Dep. de Genética, Av. Pádua Dias, no 11, Caixa Postal 83, CEP 13400-970 Piracicaba, SP. E-mail: ptlacava@esalq.usp.br, jazevedo@esalq.usp.br ${ }^{(3)}$ Instituto Biológico, Lab. de Bioquímica Fitopatológica, Av. Conselheiro Rodrigues Alves, no 1252, CEP $04014-002$ São Paulo, SP. E-mail: guzzo@biologico.sp.gov.br
\end{abstract}

\begin{abstract}
Resumo - O objetivo deste trabalho foi avaliar o efeito da aplicação do benzotiadiazole (BTH) e do silício sobre o controle da doença causada pela Xylella fastidiosa subsp. pauca em Nicotiana tabacum. Os experimentos foram conduzidos em condições de casa de vegetação, onde as plantas de $N$. tabacum receberam inoculação de

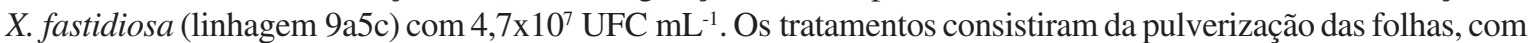
soluções de BTH (0,6 e 1,2 mM), e aplicação ao solo de soluções de metassilicato de sódio ( 2 e $4 \mu \mathrm{M}$ de Si). Cinco plantas foram utilizadas, por tratamento. Plantas de $N$. tabacum tratadas com BTH não demonstraram redução de sintomas da bacteriose. Entretanto, plantas tratadas com metassilicato de sódio, sim. A indução de resistência pelo Si poderá ser útil no controle da clorose variegada dos citros.
\end{abstract}

Termos para indexação: Nicotiana tabacum, BTH, indução de resistência sistêmica, clorose variegada dos citros.

\section{Redution of the symptons caused by Xylella fastidiosa subsp. pauca through application of benzothiadiazole and silicon}

\begin{abstract}
The objective of this work was to evaluate the effects of benzothiadiazole (BTH) and silicon applications on the control of the disease caused by Xylella fastidiosa subsp. pauca on Nicotiana tabacum. The experiments were carried out under greenhouse conditions, where $X$. fastidiosa (9a5c strain) containing $4.7 \times 10^{7} \mathrm{CFU} \mathrm{mL}^{-1}$ was inoculated in $N$. tabacum plants. The BTH and silicon treatments consisted of BTH $(0.6$ and $1.2 \mathrm{mM})$ application to plant leaves, and sodium metasilicate solution ( 2 and $4 \mu \mathrm{M}$ of $\mathrm{Si}$ ) application to soil. Plants of $N$. tabacum treated with BTH showed no reduction in symptoms. However, plants treated with sodium metasilicate (source of Si) were rendered asymptomatic. Disease resistance induced by $\mathrm{Si}$ can be useful to control citrus variegated chlorosis.
\end{abstract}

Index terms: Nicotiana tabacum, BTH, systemic acquired resistance, citrus variegated chlorosis.

\section{Introdução}

A clorose variegada dos citros (CVC) é uma doença que afeta todas as variedades de laranjas doces (Citrus sinensis L.), é causada pela bactéria Xylella fastidiosa subsp. pauca e se restringe aos vasos do xilema (Hartung et al., 1994; Schaad et al., 2004). Essa bactéria é transmitida por insetos vetores (Homoptera: Cicadellidae, Cicadellinae) (Brlansky et al., 2002) e via sementes (Li et al., 2003).

No Brasil, a CVC é responsável por perdas de $\mathrm{R} \$ 20$ milhões por ano na indútria citrícula (Della Coletta et al., 2001). Apesar de X. fastidiosa ter sido a primeira bactéria fitopatogênica a ter o seu genoma completamente seqüenciado (Simpson et al., 2000), ainda não existe um método eficiente para o controle da CVC, que continua a aumentar em severidade nos pomares (Fundecitrus, 2005).

Uma abordagem interessante no controle de doenças vegetais é a ativação de mecanismos de defesa inerentes à planta, por meio da aplicação de produtos bióticos ou abióticos não tóxicos, que atuam como indutores de mecanismos de resistência em plantas. Esses mecanismos 
estão associados à expressão coordenada de um conjunto de genes de defesa, fenômeno este conhecido por resistência sistêmica adquirida ("system acquired resistance" - SAR) (Kuc, 1995; Sticher et al., 1997). Entre os indutores de resistência abióticos, tem sido demonstrado que o composto químico sintético benzotiadiazole (BTH) atua como agente ativador dos mecanismos de defesa em plantas e as protege, sistemicamente, contra uma larga gama de doenças causadas por fungos e bactérias, sem demonstrar efeitos tóxicos diretos e significativos contra a planta (Ruess et al., 1995; Silva et al., 2000; Iriti \& Faoro, 2003; Edreva, 2004). Segundo Yamagushi (1998), o BTH não possui ação direta sobre o patógeno e atua, supostamente, com papel semelhante ao ácido salicílico na via de transdução de sinais que levam à SAR.

Recentemente, foi sugerida a utilização de sílicio (Si) na redução da incidência e desenvolvimento de doenças em mono e dicotiledôneas (Epstein, 1999; Lima Filho et al., 1999; Pozza et al., 2004; Fauteux et al., 2005; Moraes et al., 2006). A silicificação das células epidérmicas, observada em plantas tratadas com metassilicato, via foliar ou pela incorporação ao solo, constitui uma barreira física à penetração de patógenos e tem sido apontada como um dos possíveis mecanismos de ação do Si na proteção de plantas contra doenças (Fauteux et al., 2005). O Si parece, ainda, ativar nas plantas mecanismos de defesa em resposta ao ataque de patógenos, como o aumento na síntese de compostos fenólicos e das enzimas peroxidase, polifenoloxidase, quitinase e beta-glicosidase (Lima Filho et al., 1999).

Foi demonstrado que plantas de Nicotiana tabacum apresentam sintomas foliares de X. fastidiosa, significativamente mais rápidos que citros, em condições de casa de vegetação, o que a torna uma excelente planta modelo para o estudo dessa bacteriose (Lopes et al., 2000). Foi demonstrada, também, a ação do BTH como indutor da SAR nessa planta, quando inoculado artificialmente o vírus do mosaico TMV (Friedrich et al., 1996).

O objetivo deste trabalho foi verificar a ação do BTH e do silício, como indutores de resistência sistêmica em $N$. tabacum contra X. fastidiosa subsp. pauca.

\section{Material e Métodos}

Sementes de N. tabacum var. Clevelandii (Lopes et al., 2000) foram semeadas em substrato comercial Plantmax. Após período de aproximadamente 30 dias, as mudas foram transplantadas para sacos de plástico de 1,5 L, que continham o mesmo substrato, e mantidas em condições de casa de vegetação.

Soluções aquosas de BTH, nas concentrações $0,6 \mathrm{mM}$ e $1,2 \mathrm{mM}$, foram preparadas a partir de produto comercial, que continha $50 \%$ de princípio ativo na forma de pó molhável. As soluções de BTH, preparadas em água destilada esterilizada, foram submetidas à agitação durante $10 \mathrm{~min}$, antes de serem utilizadas para aspersão foliar, uma semana antes da inoculação de $X$. fastidiosa. Todas as folhas das plantas foram aspergidas, e cada planta recebeu $15 \mathrm{~mL}$ da solução de BTH.

Ao substrato vegetal Plantmax, com plantas de 30 dias, foi incorporado metassilicato de sódio (fonte de $\mathrm{Si}$ ), em forma de pó diluído em água destilada esterilizada, aos 45 e aos 20 dias antes da inoculação da bactéria, tendo-se utilizado concentrações de 2 e $4 \mu \mathrm{M}$ de Si. Para cada planta, foram adicionados ao substrato $200 \mathrm{~mL}$ da solução de metassilicato.

Quando as plantas atingiram 75 dias, foram submetidas à inoculação do patógeno. Foi utilizada, para esse procedimento, a linhagem 9a5c de X. fastidiosa (Simpson et al., 2000), originalmente isolada a partir de plantas de laranja 'Valência' (Citrus sinensis), no meio de cultura PW (Davis et al., 1981). As bactérias foram inoculadas nas plantas de $N$. tabacum com a injeção de $30 \mu \mathrm{L}$ de suspensão na concentração $4,97 \times 10^{7} \mathrm{UFC} \mathrm{mL}^{-1}$ diretamente no caule ( 2 a $3 \mathrm{~cm}$ acima do nível de substrato), com auxílio de agulha entomológica, por meio de pequenas perfurações para permitir a absorção da suspensão pelos vasos xilemáticos (Almeida et al., 2001). As plantas de N. tabacum foram mantidas em casa de vegetação a $28^{\circ} \mathrm{C}$, até a avaliação dos sintomas da doença.

Como controle positivo, foram utilizadas plantas não submetidas ao tratamento com BTH e metassilicato de sódio, mas submetidas à inoculação de X. fastidiosa. $O$ controle negativo constituiu-se de plantas não tratadas com os indutores citados e sem a inoculação do patógeno.

Para avaliação da presença de X. fastidiosa, foram removidas as folhas, com a nervura central e sem o pecíolo, de todas as plantas de tabaco, e o DNA foi extraído conforme Doyle \& Doyle (1990). Em seguida, foi realizada a PCR em 3 plantas de cada tratamento, tendo-se utilizado os primers específicos para X. fastidiosa subsp. pauca, CVC-1 e 272-2int (Pooler \& Hartung, 1995). Para as reações de PCR, foram utilizados: um volume final de $35 \mu \mathrm{L}$, com 70 ng de DNA molde; 0,4 pmol de cada primer; $200 \mathrm{mM}$ de dNTP; 
$3 \mathrm{mM}$ de $\mathrm{MgCl}_{2} ; 1 \mathrm{U}$ de Taq DNA Polimerase; $1 \mathrm{X}$ tampão buffer. Em todos os experimentos, foi realizada a reação de controle negativo, em que o DNA foi excluído; e um controle positivo com DNA extraídos das bactérias (linhagem 9a5c). Foi utilizado o termociclador programado, para gerar uma desnaturação inicial de $94^{\circ} \mathrm{C}$ por $4 \mathrm{~min}$, seguida de: 30 ciclos de $94^{\circ} \mathrm{C}$ por $1 \mathrm{~min} ; 62^{\circ} \mathrm{C}$ por $1 \mathrm{~min} ; 72^{\circ} \mathrm{C}$ por $1 \mathrm{~min}$; e uma extensão final de $72^{\circ} \mathrm{C}$ por $10 \mathrm{~min}$. Foram utilizados $3 \mu \mathrm{L}$ da reação, para a observação dos fragmentos amplificados em gel de agarose $1 \%$ com brometo de etídeo $\left(0,4 \mu \mathrm{g} \mathrm{mL}^{-1}\right)$, visualizados sob luz ultravioleta e documentados. O padrão molecular utilizado foi $1 \mathrm{~kb}$ Plus DNA Ladder.

Para a detecção de $X$. fastidiosa, foram utilizadas três plantas, de cada tratamento, para a análise de microscopia eletrônica de varredura (MEV) dos vasos de xilema de $N$. tabacum. O material vegetal foi preparado de acordo com Rodriguez \& Wetzstein (1998). As amostras foram coletadas e fixadas com cacodilato de sódio $2 \mathrm{M}$ e solução de glutaraldeído 2,5\%, durante toda a noite e, em seguida, foi lavado três vezes com solução de cacodilato $0,05 \mathrm{M}$ por 10 min e desidratado, em série crescente de acetona $(30,45,60,75,85,90$, $100 \%$ ), por 10 min a cada concentração. O material foi secado até o ponto crítico, coberto com ouro e observado em MEV a $10 \mathrm{kV}$.

$\mathrm{O}$ experimento foi realizado em delineamento experimental inteiramente casualizado, com seis tratamentos (duas concentrações de BTH, duas concentrações de $\mathrm{Si}$ e dois controles) e cinco repetições. A intensidade dos sintomas foi quantificada por avaliações de severidade. A severidade foi analisada pela porcentagem de lesões em cada planta. A porcentagem de lesões recebeu um escore de 0 a 4 , em que: zero (0) representa $0 \%$ de folhas lesionadas por planta; 1 representa de 1 a $25 \%$; 2 representa de 26 a 50\%; 3 representa de 51 a $75 \%$; e 4 representa de 76 a $100 \%$.

Para as análises estatísticas, foram realizadas análises de variância paramétrica para todos os dados obtidos. As médias de incidência e de escores de severidade foram transformados em $(\mathrm{y}+3 / 8)^{0,5}$ (Binômio de Poisson), para obtenção da normalidade dos dados. Os dados foram analisados por meio de regressão linear com o programa Statistical Analysis System (SAS Institute, 1987).

\section{Resultados e Discussão}

O BTH não conferiu proteção às plantas, em relação à $X$. fastidiosa inoculada artificialmente. A porcentagem de folhas lesionadas, observadas nas plantas tratadas com BTH a 0,6 e 1,2 mM, indicam que houve a evolução da doença, pois foi possível observar os sintomas característicos de $X$. fastidiosa entre 60 e 65 dias após a inoculação (Figura 1) (Lopes et al., 2000). Por meio da técnica de PCR (Figura 2) e MEV (Figura 3), foi
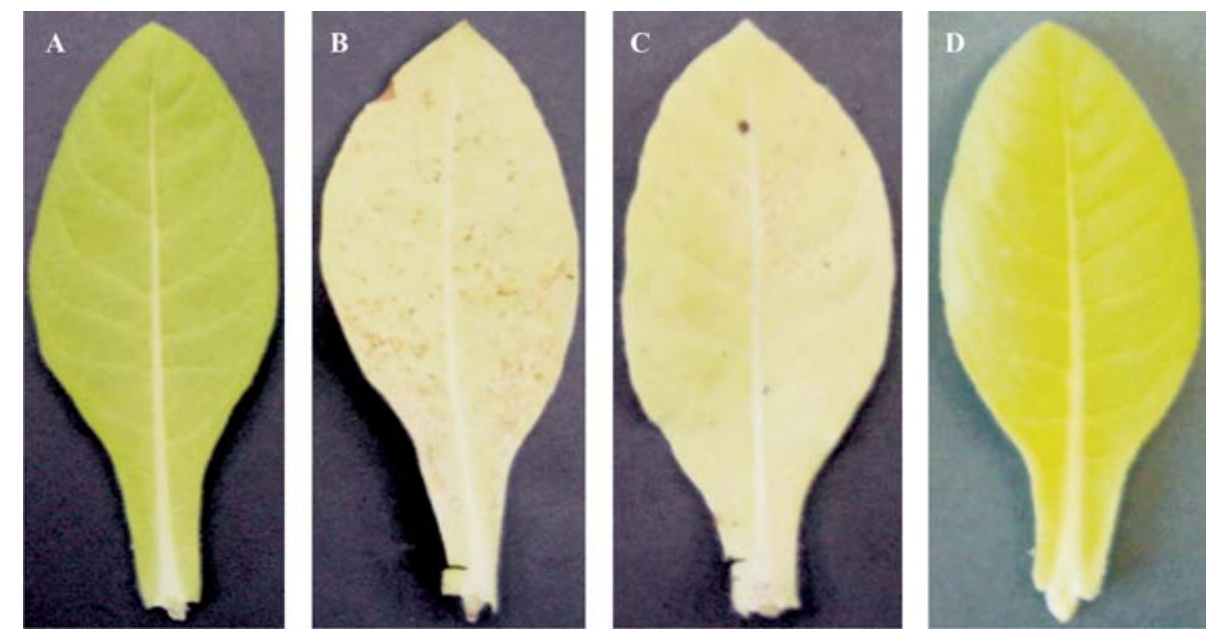

Figura 1. Folhas de Nicotiana tabacum, após 60 dias do tratamento com BTH e Si, submetidas à inoculação de Xylella fastidiosa subsp. pauca. A: controle negativo; B: controle positivo; C: BTH a 1,2 mM; D: Si a $4 \mu \mathrm{M}$. A - sem sintomas; B e C-demonstram sintomas; D - apresenta redução de sintoma, com pequena clorose. 
possível confirmar, em todas as plantas analisadas, que as lesões e sintomas observados foram conseqüência da presença de $X$. fastidiosa nos vasos de xilema.

A utilização de BTH na concentração $1,2 \mathrm{mM}$, em plantas de $N$. tabacum, propicia proteção contra os seguintes microrganismos: o vírus mosaico-do-tabaco (TMV); os fungos Cercospora nicotianae, Peronospora tabacina, Phytophthora parasitica; e a bactéria Pseudomonas syringae (Friedrich et al., 1996). Foi demonstrado que o BTH induz, em $N$. tabacum, a

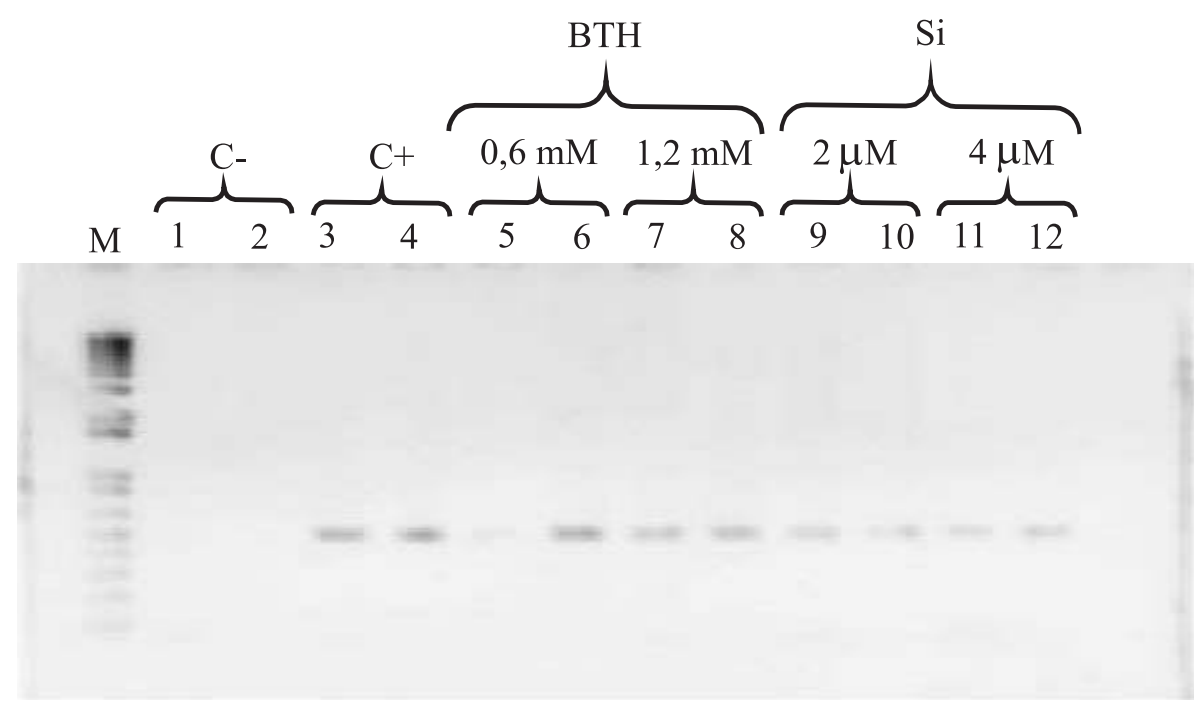

Figura 2. Produtos da amplificação de fragmentos de DNA de Xylella fastidiosa subsp. pauca. 1 e 2: controle negativo; 3 e 4: controle positivo; 5 e 6: plantas de Nicotiana tabacum tratadas com BTH a 0,6 mM; 7 e 8: plantas de $N$. tabacum tratadas com BTH a 1,2 mM; 9 e 10: plantas de N. abacum tratadas com Si a $2 \mu \mathrm{M} ; 11$ e 12: plantas de N. tabacum tratadas com Si a $4 \mu \mathrm{M}$.

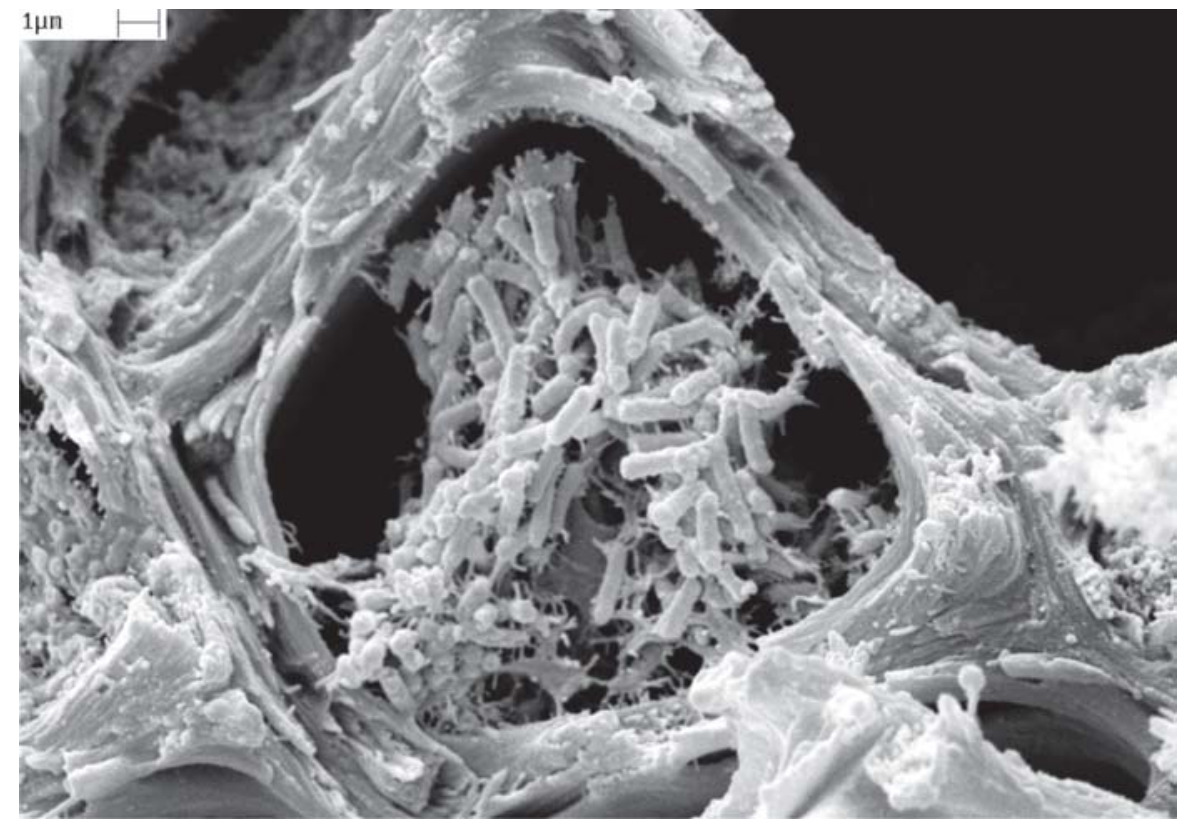

Figura 3. Microscopia eletrônica de varredura (MEV), de um corte transversal dos vasos xilemáticos de plantas sintomáticas de Nicotiana tabacum, submetidas à inoculação de Xylella fastidiosa subsp. pauca e tratadas com benzotiadiazole. 
expressão de genes relacionados à SAR, bem como alterações bioquímicas que caracterizam a SAR, ativadas por agentes bióticos como o acúmulo de mRNAs de proteínas relacionadas à patogênese, como PR-1a, quitinases e beta-1,3-glucanases (Friedrich et al., 1996), ou alterações estruturais, como o depósito de calose nas paredes celulares, nos sítios de penetração do patógeno (Benhamou \& Bélanger, 1998). Entretanto, no presente trabalho, não foi observada proteção em plantas de $N$. tabacum, indício de que os mecanismos de resistência, ativados pelo BTH nessa planta, não são efetivos em impedir a expressão de sintomas causados por X. fastidiosa.

Os resultados das análises das plantas de $N$. tabacum tratadas com metassilicato de sódio indicaram que houve proteção em relação à bacteriose, quando comparadas com o controle positivo (Figura 1), apesar de a X. fastidiosa ter sido detectada, também, nas plantas de N. tabacum tratadas com $\mathrm{Si}$ (Figura 2). Araújo et al. (2002) também detectaram, por meio de PCR, X. fastidiosa em plantas consideradas assintomáticas de Citrus sinensis.

A porcentagem de folhas lesionadas, em plantas tratadas com Si na concentração de $2 \mu \mathrm{M}$, foi menor do que nas plantas do controle positivo, enquanto na concentração de $4 \mu \mathrm{M}$ de $\mathrm{Si}$ as plantas apresentaram porcentagem de folhas lesionadas ainda menor.

As análises estatísticas de regressão demonstraram que houve diferença significativa entre as concentrações e a redução das lesões, somente quando a fonte utilizada foi o metassilicato de sódio (CV\% 27 e r ${ }^{2}$ 0,96). As plantas de $N$. tabacum responderam positivamente às concentrações de Si aplicadas e tiveram diminuído o escore de severidade à razão de $-0,0247$, para cada acréscimo na concentração da solução de Si adicionada ao substrato. Entretanto, em relação às concentrações de $\mathrm{BTH}$, as análises estatísticas de regressão mostraram que não houve diferença significativa entre as plantas tratadas com este composto, em relação às plantas controle.

O Si é mais facilmente absorvido pelas plantas nas formas solúveis e é translocado via xilema para outras partes da planta. Em plantas de cafeeiro, as concentrações menores de Si apresentam distribuição uniforme, com translocação para a folha; no entanto, com o aumento da concentração, ocorre acúmulo deste elemento no caule (Santos, 2002). A ação protetora do Si contra $X$. fastidiosa pode, portanto, não estar envolvida com os sinais das plantas, mas sim com uma barreira física ocasionada pelo $\mathrm{Si}$.
O Si apresenta alto potencial de uso na agricultura, promove melhorias no metabolismo das plantas (Lima Filho et al., 1999), melhora as respostas ao estresse abiótico, e aumenta, significativamente, o crescimento de algumas plantas (Epstein, 1994; Marschner, 1995). A ação do $\mathrm{Si}$, como indutor de resistência em $N$. tabacum contra $X$. fastidiosa, é uma importante constatação, pois a condução de experimentos futuros, para o estudo dos possíveis mecanismos de ação do Si ou as possíveis alterações estruturais induzidas por esse elemento, poderá fornecer subsídios para o controle da CVC.

\section{Conclusões}

1. O tratamento de plantas de Nicotiana tabacum com BTH não é eficiente na indução de resistência contra Xylella fastidiosa.

2. O fornecimento de silício para plantas é promissor para a indução de resistência contra $X$. fastidiosa.

\section{Agradecimentos}

À Fundação de Amparo à Pesquisa no Estado de São Paulo (Fapesp), por suporte financeiro e por bolsa concedida; ao Dr. Sílvio A. Lopes, da Fundação de Defesa da Citricultura (Fundecitrus), por ceder as sementes de N. tabacum var. Clevelandii; ao Dr. Elliot W. Kitajima (NAP/Mepa - Esalq/USP), pelo suporte técnico no experiemento de MEV.

\section{Referências}

ALMEIDA, R.P.P.; PEREIRA, E.F.; PURCELL, A.P.; LOPES, J.R.S. Multiplication and movement of a citrus strain of Xylella fastidiosa within sweet orange. Plant Disease, v.85, p.382-386, 2001.

ARAÚJO, W.L.; MARCON, J.; MACCHERONI JUNIOR, W.; ELSAS, J.D. van; VUURDE, J.W.L. van; AZEVEDO, J.L. Diversity of endophytic bacterial populations and their interaction with Xylella fastidiosa in citrus plants. Applied and Environmental Microbiology, v.68, p.4906-4914, 2002.

BENHAMOU, N.; BÉLANGER, R.R. Benzothiadiazole-mediated induced resistance to Fusarium oxysporum f. sp. Radicis-lycopersici in tomato. Plant Physiology, v.118, p.1203-1212, 1998.

BRLANSKY, R.H.; DAMSTEEGT, V.D.; HARTUNG, J.S. Transmission of the citrus variegated chlorosis bacterium Xylella fastidiosa with the sharpshooter Oncometopia nigricans. Plant Disease, v.86, p.1237-1239, 2002.

DAVIS, M.J.; FRENCH, W.J.; SCHAAD, N.W. Axenic culture of the bacteria associated with phony disease of peach and plum leaf scald. Current Microbiology, v.6, p.309-314, 1981. 
DELLA COLETTA, F.H.; TAKITA, M.A.; SOUZA, A.A. de; AGUILAR-VILDOSO, C.I.; MACHADO, M.A. Differentiation of strains of Xylella fastidiosa by a variable number of tandem repeat analysis. Applied and Environmental Microbiology, v.67, 40914095, 2001.

DOYLE, J.J.T.; DOYLE, J.L. Isolation of plant DNA from fresh tissue. Focus, v.12, p.13-18, 1990.

EDREVA, A. A novel strategy for plant protection: induced resistance. Journal of Cell and Molecular Biology, v.3, p.61-69, 2004.

EPSTEIN, E. Silicon. Annual Review of Plant Physiology and Plant Molecular Biology, v.50, p.641-664, 1999.

EPSTEIN, E. The anomaly of silicon in plant biology. Proceedings of the National Academy of Sciences of the United States of America, v.91, p.11-17, 1994.

FAUTEUX, F.; RÉMUS-BOREL, W.; MENZIES, J.G.; BÉLANGER, R.R. Silicon and plant disease resistance against pathogenic fungi. FEMS Microbiology Letters, v.249, p.1-6, 2005.

FRIEDRICH, L.; LAWTON, K.; RUESS, W.; MASNER, P.; SPECKER, N.; RELLA, M.G.; MEIER, B.; DINCHER, S.; STAUB, T.; UKNES, S.; METRAUX, J.-P.; KESSMANN, H.; RYALS, J. A benzothiadiazole derivative induces systemic acquired resistance in tobacco. Plant Journal, v.10, p.61-70, 1996.

FUNDECITRUS. Estatísticas da CVC. Disponível em <http:// www.fundecitrus.com.br/est_cvc_br.html>. Acesso em: 21 jun. 2005.

HARTUNG, J.S.; BERETTA, J.; BRLANSKY, R.H.; SPISSO, J.; LEE, R.F. Citrus variegated chlorosis bacterium: axenic culture, pathogenicity, and serological relationships with other strains of Xylella fastidiosa. Phytopathology, v.84, p.591-597, 1994.

IRITI, M.; FAORO, F. Benzothiadiazole (BTH) induces cell-death independent resistance in Phaseolus vulgaris against Uromyces appendiculatus. Journal of Phytopathology, v.151, p.171-180, 2003.

KUC, J. Systemic induced resistance. Aspects of Applied Biology, v.42, p.235-242, 1995.

LI, W.B.; PRIAJUNIOR, W.D.; LACAVA, P.M.; QIN, X.; HARTUNG, J.S. Presence of Xylella fastidiosa in sweet orange fruit and seeds and its transmission to seedlings. Phytopathology, v.93, p.953-958, 2003.

LIMA FILHO, O.F. de; LIMA, M.T.G. de; TSAI, S.M. Supressão de patógenos em solos induzida por agentes abióticos: o caso do silício. Informações Agronômicas, v.87, p.8-12, 1999.

LOPES, S.A.; RIBEIRO, D.M.; ROBERTO, P.G.; FRANÇA, S.C. Nicotiana tabacum as an experimental host for the study of plant-Xylella fastidiosa interactions. Plant Disease, v.84, p.827-830, 2000.

MARSCHNER, H. Mineral nutrition of higher plants. New York: Academic Press, 1995. 887p.

MORAES, S.R.G.; POZZA, E.A.; ALVES, E.; POZZA, A.A.A.; CARVALHO, J.G.; LIMA, P.H.; BOTELHO, A.O. Efeito de fontes de silício naincidênciae na severidade da antracnose do feijoeiro. Fitopatologia Brasileira, v.31, p.69-75, 2006.

POOLER, M.R.; HARTUNG, J.S. Specific detection and identification of Xylella fastidiosa strains causing citrus variegated clorosis. Current Microbiology, v.31, p.377-381, 1995.

POZZA, A.A.A.; ALVES, E.; POZZA, E.A.; DE CARVALHO, J.G; MONTANARI, M.; GUIMARÃES, P.T.G.; SANTOS, D.M. Efeito do silício no controle da cercosporiose em três variedades de cafeeiro. Fitopatologia Brasileira, v.29, p.185-188, 2004.

RODRIGUEZ, A.P.M.; WETZSTEIN, H.Y. A morphological and histological comparison of the initiation and development of pecan (Carya illinoinensis) somatic embryogenic cultures induced with naphthaleneacetic acid or 2,4-dichlorophenoxyacetic acid. Protoplasma, v.204, p.71-83, 1998.

RUESS, W.; KUNZ, W.; STAUB, T.; MÜLLER, K.; POPPINGER, N.; SPEICH, J.; AHL GOY, P. Plant activator CGA 245704: a new technology for disease management. European Journal of Plant Pathology, v.101, p.424, 1995.

SANTOS, D.M. Efeito do silício na intensidade da cercosporiose (Cercospora coffeicola Berk \& Cooke) em mudas de cafeeiro (Coffea arabica L.). 2002. 43p. Dissertação (Mestrado) - Universidade Federal de Lavras, Lavras.

SAS INSTITUTE. SAS/STAT: guide for personal computers, version 6. Cary: SAS Institute, 1987.

SCHAAD, N.W.; POSTNIKOVA, E.; LACY, G.; FATMI, M.; CHANG, C.-J. Xylella fastidiosa subspecies: $X$. fastidiosa subsp. piercei, subsp. nov., $X$. fastidiosa subsp. multiplex, subsp. nov., and X. fastidiosa subsp. pauca, subsp. nov. Systematic and Applied Microbiology, v.27, p.290300, 2004

SILVA, L.H.C.P.; RESENDE, M.L.V.; MARTINS JUNIOR, H.; CAMPOS, J.R.; SOUZA, R.M.; CASTRO, R.M. Épocas e modo de aplicação do ativador de plantas benzothiadiazole (BTH) na proteção contra a mancha bacteriana do tomateiro. Horticultura Brasileira, v.18, p.375-376, 2000.

SIMPSON, A.J.G.; REINACH, F.C.; ARRUDA, P.; ABREU, F.A.; ACENCIO, M.; ALVARENGA, R.; ALVES, L.M.C.; ARAYA, J.E.; BAIA, G.S.; BAPTISTA, C.S.; BARROS, M.H.; BONACCORSI, E.D.; BORDIN, S.; BOVÉ, J.M.; BRIONES, M.R.S.; BUENO, M.R.P.; CAMARGO, A.A.; CAMARGO, L.E.A.; CARRARO, D.M.; CARRER, H.; COLAUTO, N.B.; COLOMBO, C.; COSTA, F.F.; COSTA, M.C.R.; COSTA-NETO, C.M.; COUTINHO, L.L.; CRISTOFANI, M.; DIAS-NETO, E.; DOCENA, C.; EL-DORRY, H.; FACINCANI, A.P.; FERREIRA, A.J.S.; FERREIRA, V.C.A.; FERRO, J.A.; FRAGA, J.S.; FRANÇA, S.C.; FRANCO, M.C.; FROHME, M.; FURLAN, L.R.; GARNIER, M.; GOLDMAN, G.H.; GOLDMAN, M.H.S.; GOMES, S.L.; GRUBER, A.; HO, P.L.; HOHEISEL, J.D.; JUNQUEIRA, M.L.; KEMPER, E.L.; KITAJIMA, J.P.; KRIEGER, J.E.; KURAMAE, E.E.; LAIGRET, F.; LAMBAIS, M.R.; LEITE, L.C.C.; LEMOS, E.G.M.; LEMOS, M.V.F.; LOPES, S.A.; LOPES, C.R.; MACHADO, J.A.; MACHADO, M.A.; MADEIRA, A.M.B.N.; MADEIRA, H.M.F.; MARINO, C.L.; MARQUES, M.V.; MARTINS, E.A.L.; MARTINS, E.M.F.; MATSUKUMA, A.Y.; MENCK, C.F.M.; MIRACCA, E.C.; MIYAKI, C.Y.; MONTEIRO-VITORELLO, C.B.; MOON, D.H.; NAGAI, M.A.; NASCIMENTO, A.L.T.O.; NETTO, L.E.S.; NHANI, A.; NOBREGA, F.G.; NUNES, L.R.; OLIVEIRA, M.A.; OLIVEIRA, M.C. de; OLIVEIRA, R.C. de; PALMIERI, D.A.; PARIS, A.; PEIXOTO, B.R.; PEREIRA, G.A.G.; PEREIRA, H.A.; PESQUERO, J.B.; QUAGGIO, R.B.; ROBERTO, P.G.; RODRIGUES, V.; ROSA, A.J. de M.; ROSA, V.E. de; SÁ, R.G. de; SANTELLI, R.V.; SAWASAKI, H.E.; SILVA, A.C.R. da; SILVA, A.M. da; SILVA, F.R. da; SILVA, W.A.; SILVEIRA, J.F. da; SILVESTRI, M.L.Z.; SIQUEIRA, W.J.; SOUZA, A.A. da; SOUZA, A.P. de; TERENZI, M.F.; TRUFFI, D.; TSAI, S.M.; TSUHAKO, 
M.H.; VALLADA, H.; VAN SLUYS, M.A.; VERJOVSKIALMEIDA, S.; VETTORE, A.L.; ZAGO, M.A.; ZATZ, M.; MEIDANIS, J.; SETUBAL, J.C. The genome sequence of the plant pathogen Xylella fastidiosa. Nature, v.406, p.151-157, 2000.

STICHER, L.; MAUCH-MANI, B.; METRAUX, J.P. Systemic acquired resistance. Annual Review of Phytopathology, v.35, p.235270, 1997.
WUTSCHER, H.K. Growth and mineral nutrition of young orange trees grown with high levels of silicon. HortScience, v.24, p.275277, 1989 .

YAMAGUCHI, I. Activators for sistemic acquired resistance. In: HUTSON, D.; MIYAMOTO, J. (Ed.). Fungicidal activity: chemical and biological approaches to plant protection . New York: Wiley, 1998. p.193-219.

Recebido em 8 de março de 2007 e aprovado em 10 de julho de 2007 